\title{
The i-gel Supraglottic Airway as a Conduit for Fibreoptic Tracheal Intubation - A Randomized Comparison with the Single-use Intubating Laryngeal Mask Airway and CTrach Laryngeal Mask in Patients with Predicted Difficult Laryngoscopy
}

\section{Pavel Michálek ${ }^{1,2}$, Will Donaldson ${ }^{2}$, Francis McAleavey ${ }^{2}$,} Alexander Abraham ${ }^{2}$, Rachel J. Mathers ${ }^{3}$, Claire Telford ${ }^{4}$

${ }^{1}$ Department of Anesthesiology and Intensive Care, First Faculty of Medicine,

Charles University and General University Hospital in Prague, Prague,

Czech Republic;

${ }^{2}$ Department of Anaesthetics, Antrim Area Hospital, Northern HSC Trust, Antrim, United Kingdom;

${ }^{3}$ Department of Anaesthesia, Daisy Hill Hospital, Southern HSC Trust, Newry, United Kingdom;

${ }^{4}$ AstraZeneca, Washington D.C., USA

Received August 23, 2016; Accepted November 14, 2016.

Key words: i-gel - Intubating laryngeal mask airway - CTrach - Fibreoptic intubation

Abstract: Fibreoptic intubation through a supraglottic airway is an alternative plan for airway management in difficult or failed laryngoscopy. The aim of this study was to compare three supraglottic airways as conduits in patients with at least one predictor for difficult laryngoscopy. The i-gel was compared with the single-use intubating laryngeal mask airway (sILMA) and CTrach laryngeal mask in 120 adult patients scheduled for elective surgeries under general anaesthesia using a prospective, randomized and single-blinded design. Primary outcome was success

This study was supported by a grant from the Northern HSC Trust Discretionary Fund, No. NRP-09-0120.

Mailing Address: Assoc. Prof. Pavel Michálek, MD., PhD., DESA, MSc., Department of Anesthesiology and Intensive Care, First Faculty of Medicine, Charles University and General University Hospital in Prague, U nemocnice 2, 12021 Prague 2, Czech Republic; Phone: +420 224967 124; e-mail: pavel.michalek@vfn.cz 
rate of tracheal intubation through the device, while secondary outcomes were times required for device insertion and tracheal tube placement, fibreoptic scores and the incidence of perioperative complications and postoperative complaints. The success rates showed no statistical difference between devices (i-gel 100\%, CTrach 97.5\%, ILMA 95\%). Insertion time was shortest for the i-gel (12.4 s) compared with ILMA (19.3 s) and CTrach (24.4 s). Intubation time was shorter in the i-gel group (29.4 s) in comparison with the CTrach $(39.8 \mathrm{~s}, \mathrm{p}<0.05)$ and sILMA (51.9 s, $p<0.001)$ groups. Best fibreoptic scores were observed also in the i-gel group. In total, 24 patients (20\%) presented with difficult laryngoscopy. The i-gel showed significantly shorter times for insertion and fibreoptic intubation than the other two devices in this group. No difference was observed in the incidence of postoperative complaints. The i-gel is a suitable alternative to the sILMA and $C$ Trach for fibrescope-guided tracheal intubation. Shorter insertion and intubation times with the i-gel may provide advantage in case of difficult oxygenation.

\section{Introduction}

Supraglottic airway devices (SADs) play an important role in modern anaesthetic practice (Michálek and Miller, 2014). Apart from airway maintenance during selected elective procedures, they may be used in difficult airway management situations. The SADs in these situations allow both spontaneous and controlled ventilation. SADs also can allow planned blind or fibreoptic intubation in expected and unexpected difficult laryngoscopies (Timmermann, 2011). The use of SADs (intubating laryngeal mask airway, ILMA ${ }^{\circledR}$, Intavent Direct; classic laryngeal mask airway, LMA Classic ${ }^{\circledR}$, Intavent Direct) for both ventilation and fibrescope-
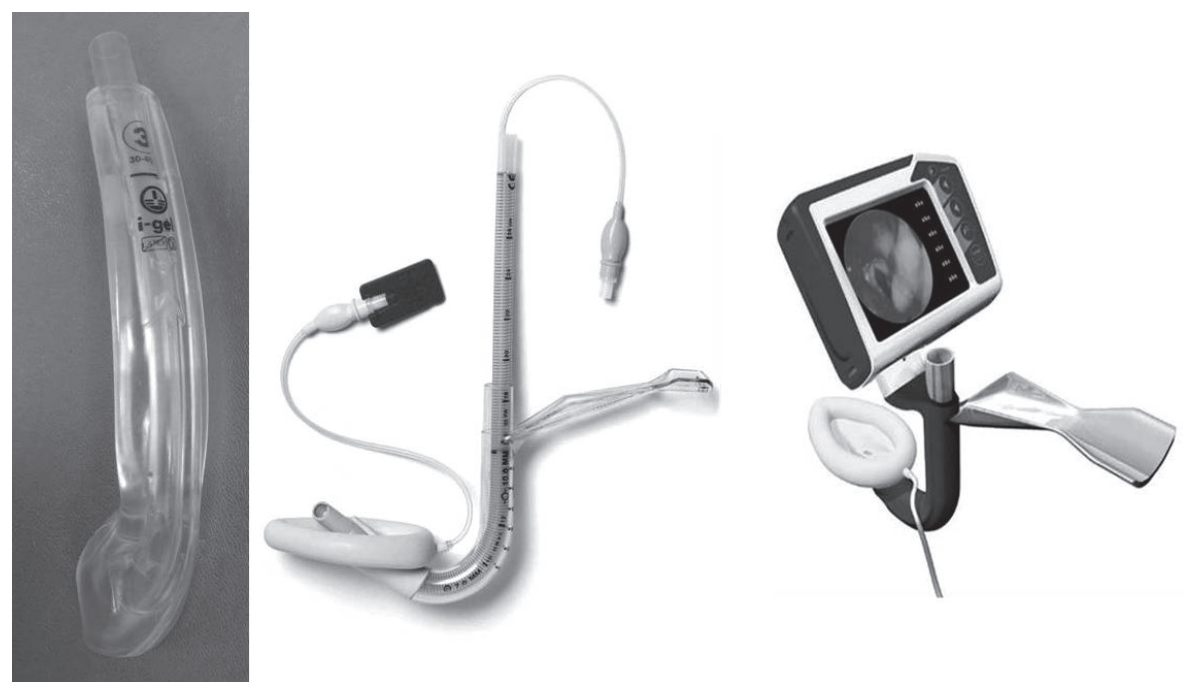

Figure 1 - Supraglottic airway devices used in the study - i-gel, sILMA, CTrach. 
guided tracheal intubation is recommended by the Difficult Airway Society as an acceptable back-up plan during unexpected difficult intubation (Frerk et al., 2015).

Based on our previous experience, evidenced by case reports (Michalek et al., 2008; Campbell et al., 2009) and a manikin study (Michalek et al., 2010), we aimed to compare the i-gel as a conduit for fibrescope-guided tracheal intubation with the single-use intubating laryngeal mask airway (sILMA ${ }^{\mathrm{TM}}$, Laryngeal Mask Company, Mahé, Seychelles) and with the CTrach laryngeal mask (The Laryngeal Mask Company, Singapore) (Figure 1). The null hypothesis for this study was that each of these three devices would perform without a statistical difference in terms of success rate and time needed for their insertion and tracheal intubation.

\section{Material and Methods}

The study protocol was approved by both a local (Northern HSC Trust) and regional Ethical Committee (Office for Research and Ethical Committees Northern Ireland, 09/NIR03/44). The study was then registered with a public trial database (www.clinicaltrials.gov, NCT00983229). All participants received a Study Information Pack in advance and signed their written consent. In total, 120 participants were included in the study (Figure 2). Inclusion criteria were: ASA I-III patients, both genders, age 18-89 years, all elective procedures requiring tracheal intubation and at least one predictor of difficult laryngoscopy Mallampati score II or higher, thyromental distance less than $6.5 \mathrm{~cm}$, limited

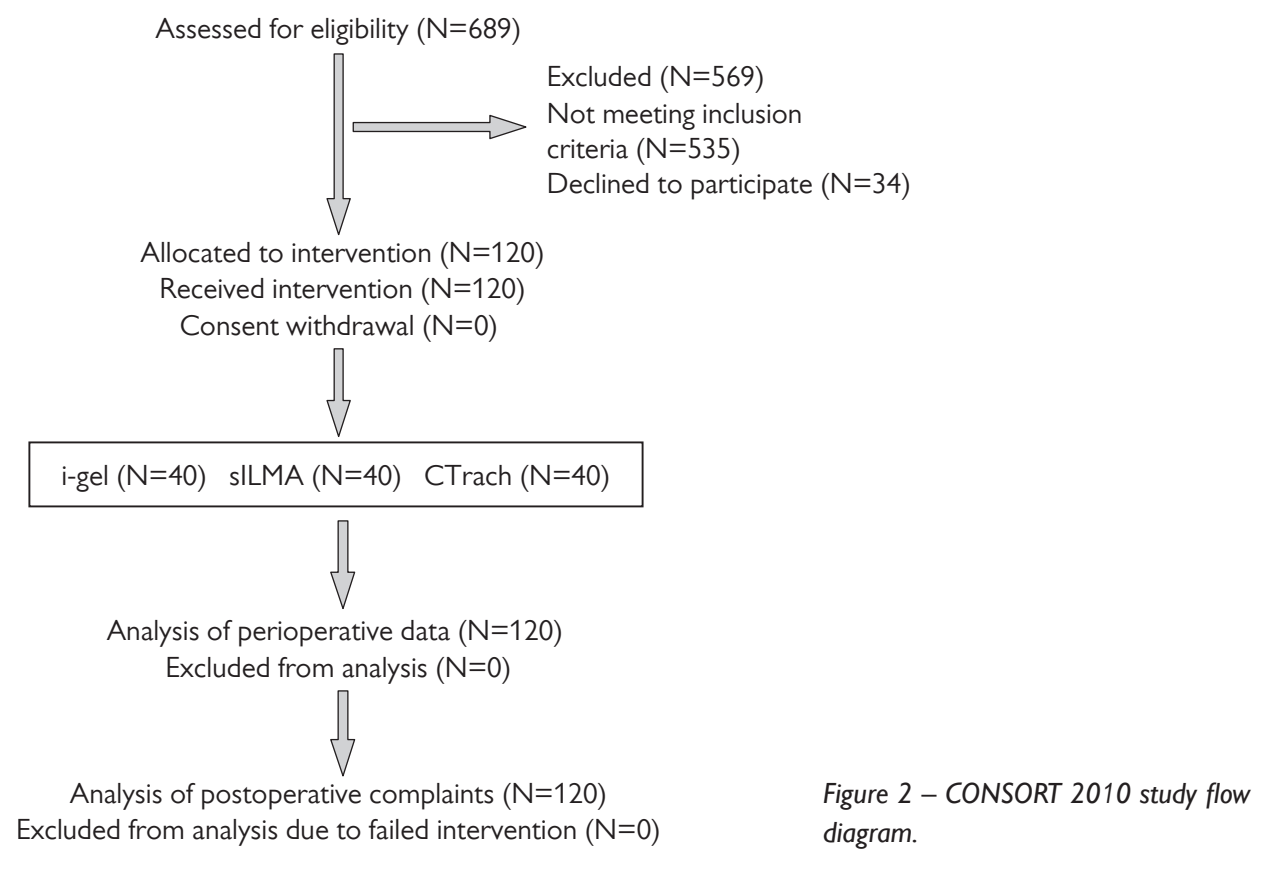

Michálek P.; Donaldson W.; McAleavey F.; Abraham A.; Mathers R. J.; Telford C. 
mouth opening and previous history of difficult laryngoscopy. Exclusion criteria were: ASA status IV or V patients, emergency surgical procedures and patients at increased risk for aspiration of gastric contents. Randomization was performed using a randomization software and sealed envelopes immediately prior to patient admission to the anaesthetic room. The operators were trained anaesthetists with previous experience in fibreoptic intubation. Induction of general anaesthesia was standardized and included fentanyl, propofol at a dose of $2-3 \mathrm{mg} / \mathrm{kg}$ (until loss of verbal contact) and non-depolarizing muscle relaxant. Non-depolarizing relaxant was given upon confirmation of feasible bag-mask ventilation. Following successful induction and confirmation of adequate muscle relaxation (TOF 0), an independent operator performed direct laryngoscopy using a standard Macintosh laryngoscopic blade and recorded the view according to the Cormack and Lehane classification (1-4) (Cormack and Lehane, 1984). Different operators then inserted the supraglottic airway devices and intubated through them. Procedure was divided into several steps:

Step 1: Insertion of a supraglottic airway device;

Step 2: Assessment of fibreoptic view through the device;

Step 3:Tracheal intubation through the supraglottic airway device;

Step 4: Removal of the SAD.

Following insertion of the SAD and confirmation of its satisfactory function effective ventilation, oxygenation and no audible leak around the device - the operator inserted a flexible fibrescope with an external diameter of $5.2 \mathrm{~mm}$ (Olympus Medical Systems, Tokyo, Japan) with a loaded soft tracheal tube (Fastrach $^{\mathrm{TM}}$ silicone tube, Laryngeal Mask Co., Mahé, Seychelles) through a device in case of i-gel and sILMA, or switched on the light of the CTrach LMA. Endotracheal tubes size 7.0 were used for size 4 SADs, and sizes 7.5 tubes for size 5, respectively. Endotracheal tubes were railroaded over the fibreoptic scope in the i-gel and sILMA groups, while in the CTrach group, they were inserted into the trachea under the direct vision of the CTrach camera.

The primary outcome of this study was the success rate of tracheal intubation through each device. Secondary outcomes included: insertion time of supraglottic

Table 1 - Fibreoptic view scoring system (Kapila et al., 1997), and percentage of glottis opening (POGO) score (Levitan et al., 1998)

\begin{tabular}{ll}
\hline Fibreoptic view scoring system & POGO score \\
\hline $1-$ Full view of vocal cords & 0 -Vocal cords not visible \\
\hline $\begin{array}{l}2-\text { Partial view of vocal cords, including } \\
\text { arytenoids }\end{array}$ & $100-$ Full view of vocal cords \\
\hline $3-$ Epiglottis only visible & $\begin{array}{l}\text { Values between } 0 \text { and } 100 \text { are calculated } \\
\text { according to proportion of the cords visible } \\
\text { with the scope }\end{array}$ \\
\hline $\begin{array}{l}4-\text { Other structures visible only } \\
\text { (pharynx, LMA cuff) }\end{array}$ & \\
\hline
\end{tabular}


device, intubation time through the device, fibreoptic scores and incidence of postoperative complaints. Insertion time was defined as the time interval from when the device was handed to an anaesthetist until the first successful breath as visible with capnography. Intubation time was defined as the interval from the circuit disconnection until the first successful breath. We evaluated two different fibreoptic scores - "fibreoptic view scoring system" (Kapila et al., 1997) and "percentage of glottis opening” (POGO) score (Levitan et al., 1998) (Table 1). Serious complications such as massive intraoral bleed or aspiration of gastric contents were recorded. The following postoperative complaints were evaluated at 24 hours: sore throat, hoarseness, swallowing difficulties, tongue numbness and cough.

\section{Statistics}

Sample size was determined to be 120 patients in total - allowing an alpha-error of 0.05 and power of $80 \%$ (beta-error of 0.05 ). A $90 \%$ success rate was determined for the sILMA and CTrach based on the results of previous studies and a lowest meaningful success rate of the i-gel was set up as $65 \%$ (25\% difference). All data were tested for normal distribution prior to final statistical analysis using the Shapiro-Wilk test. According to data distribution, either parametric (Fischer's exact test, chi-square test) or non-parametric (Kruskal-Wallis) tests were employed. InStat software (GraphPad Software Inc., La Jolla, USA) was used for all comparisons.

\section{Results}

Demographic data is shown in Table 2. There were no significant differences between the groups in terms of age, duration of surgery or weight. Total success rate of tracheal intubation through the device, as a primary outcome, did not differ significantly (i-gel 100\%, CTrach 97.5\%, sILMA 95\%) (Table 3). Regarding secondary outcomes of the study, the i-gel showed significantly shorter insertion (Figure 3)

\section{Table 2 - Patient demographic data, preoperative airway evaluation and perioperative data}

\begin{tabular}{lccc}
\hline & i-gel $(\mathrm{n}=40)$ & sILMA $(\mathrm{n}=40)$ & CTrach $(\mathrm{n}=40)$ \\
\hline Gender (M/F) & $10 / 30$ & $16 / 24$ & $21 / 19$ \\
Age (years, range) & $48(18-74)$ & $47(18-83)$ & $49(21-77)$ \\
ASA (I/II/III/IV) & $9 / 30 / 1 / 0$ & $17 / 20 / 3 / 0$ & $10 / 26 / 4 / 0$ \\
Weight (kg) & $78[72-84]$ & $76[71-81]$ & $83[79-87]$ \\
Mallampati (I/II/III/IV) & $8 / 21 / 9 / 2$ & $11 / 17 / 12 / 0$ & $3 / 32 / 5 / 0$ \\
Limited mouth opening & $21(52 \%)$ & $22(55 \%)$ & $18(45 \%)$ \\
Limited jaw protrusion & $32(80 \%)$ & $31(78 \%)$ & $27(68 \%)$ \\
Thyromental distance $\leq 6.5 \mathrm{~cm}$ & $8(20 \%)$ & $5(12 \%)$ & $1(2 \%)$ \\
Duration of surgery $(\mathrm{min})$ & $79[71-87]$ & $84[76-92]$ & $100[88-112]$ \\
\hline
\end{tabular}

Data presented as mean $[95 \% \mathrm{Cl}]$, mean (range) or number 
and intubation times (Figure 4) than the other two devices tested (Table 4). The i-gel device also demonstrated the best coverage of the laryngeal inlet as evidenced by the highest concentration of fibreoptic scores of 1 and 2 in the i-gel group and by the highest concentration of POGO scores over $75 \%$ in the i-gel group (Figure 5).

Additional sub-group analysis for patients who experienced difficult laryngoscopy

Table 3 - Primary outcome of the study - Differences in success rates of intubation through the supraglottic airway devices

\begin{tabular}{lccc}
\hline & \multicolumn{3}{c}{ Device } \\
\hline Outcome $(\%)$ & i-gel & sILMA & CTrach \\
\hline Success & $40(100 \%)$ & $38(90 \%)$ & $39(97.5 \%)$ \\
Failure & 0 & $2(10 \%)$ & $1(2.5 \%)$ \\
\hline
\end{tabular}

Statistical significance as confirmed with the Fisher's exact test; i-gel vs. sILMA $-p=0.494$, i-gel vs. CTrach $-p=1.00$, sILMA vs. CTrach $-\mathrm{p}=1.00$

i-gel

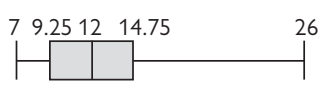

SILMA
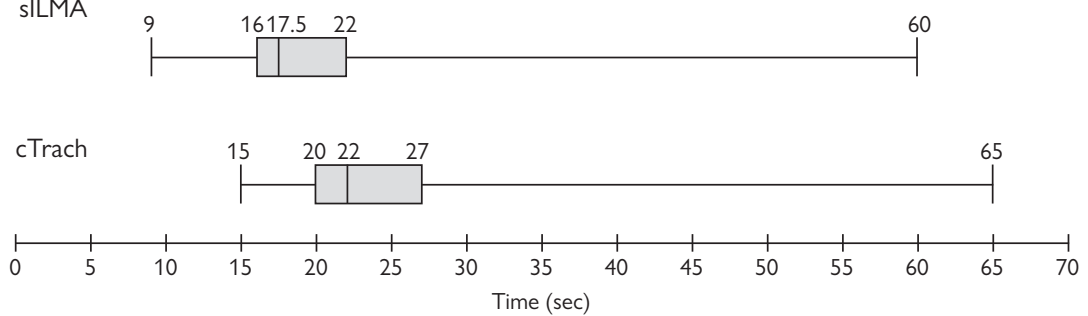

Figure 3 - Box-plot of insertion times of supraglottic airway devices.

i-gel

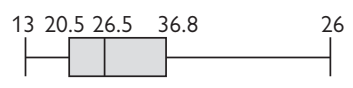

SILMA
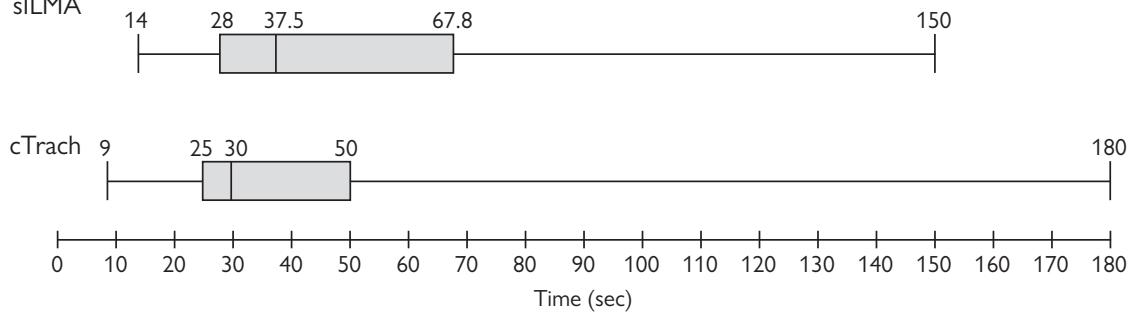

Figure 4 - Box-plot of intubation times through supraglottic airway devices. 
170) Prague Medical Report / Vol. 117 (2016) No. 4, p. 164-175

Table 4 - Secondary outcomes of the study - Insertion time, intubation time, coverage of laryngeal inlet

\begin{tabular}{lccc}
\hline & \multicolumn{3}{c}{ Device } \\
\cline { 2 - 4 } & i-gel $(\mathrm{n}=40)$ & slLMA $(\mathrm{n}=40)$ & CTrach $(\mathrm{n}=40)$ \\
\hline Time insertion $(\mathrm{s})$ & $12.4[11-13.8]$ & $19.3[16.3-22.3]$ & $24.4[21.4-27.4]$ \\
\hline Difference & & $6.9[4.4-10.6]^{* * *}$ & $12.0[9.5-15.7]^{* * *}$ \\
\hline Time intubation $(\mathrm{s})$ & $29.4[26-32.8]$ & $51.9[40.7-60.1]$ & $39.8[29.7-49.9]$ \\
\hline Difference & & $22.5[12.3-34.8]^{*}$ & $10.3[2.7-23.6]^{* * *}$ \\
\hline $\begin{array}{l}\text { Fibreoptic view score } \\
(1 / 2 / 3 / 4)\end{array}$ & $29 / 9 / 2 / 0$ & $16 / 17 / 4 / 3^{\mathrm{a}}$ & $11 / 22 / 6 / 1^{\mathrm{b}}$ \\
\hline $\begin{array}{l}\text { POGO score } \\
(0 / 10 / 25 / 50 / 75 / 100 \%)\end{array}$ & $1 / 1 / 0 / 4 / 13 / 21$ & $7 / 2 / 5 / 3 / 15 / 8^{\mathrm{c}}$ & $1 / 4 / 2 / 8 / 17 / 8^{\mathrm{d}}$ \\
\hline
\end{tabular}

Data presented as mean (s) $[95 \% \mathrm{Cl}]$ for times, numbers (\%) for fibreoptic view scoring system and percentage of glottic opening (POGO); ${ }^{*} \mathrm{p}<0.05,{ }^{* * *} \mathrm{p}<0.001-$ Kruskal-Wallis test; ${ }^{\mathrm{a}} \mathrm{p}=0.006$ for scores $1, \mathrm{p}=0.15$ for scores $1+2$, ${ }^{b} p=0.0001$ for scores $1, p=0.15$ for scores $1+2-$ Fisher's exact test; ${ }^{c} p=0.01$ for scores $75-100 \%,{ }^{d} p=0.04-$ Fisher's exact test

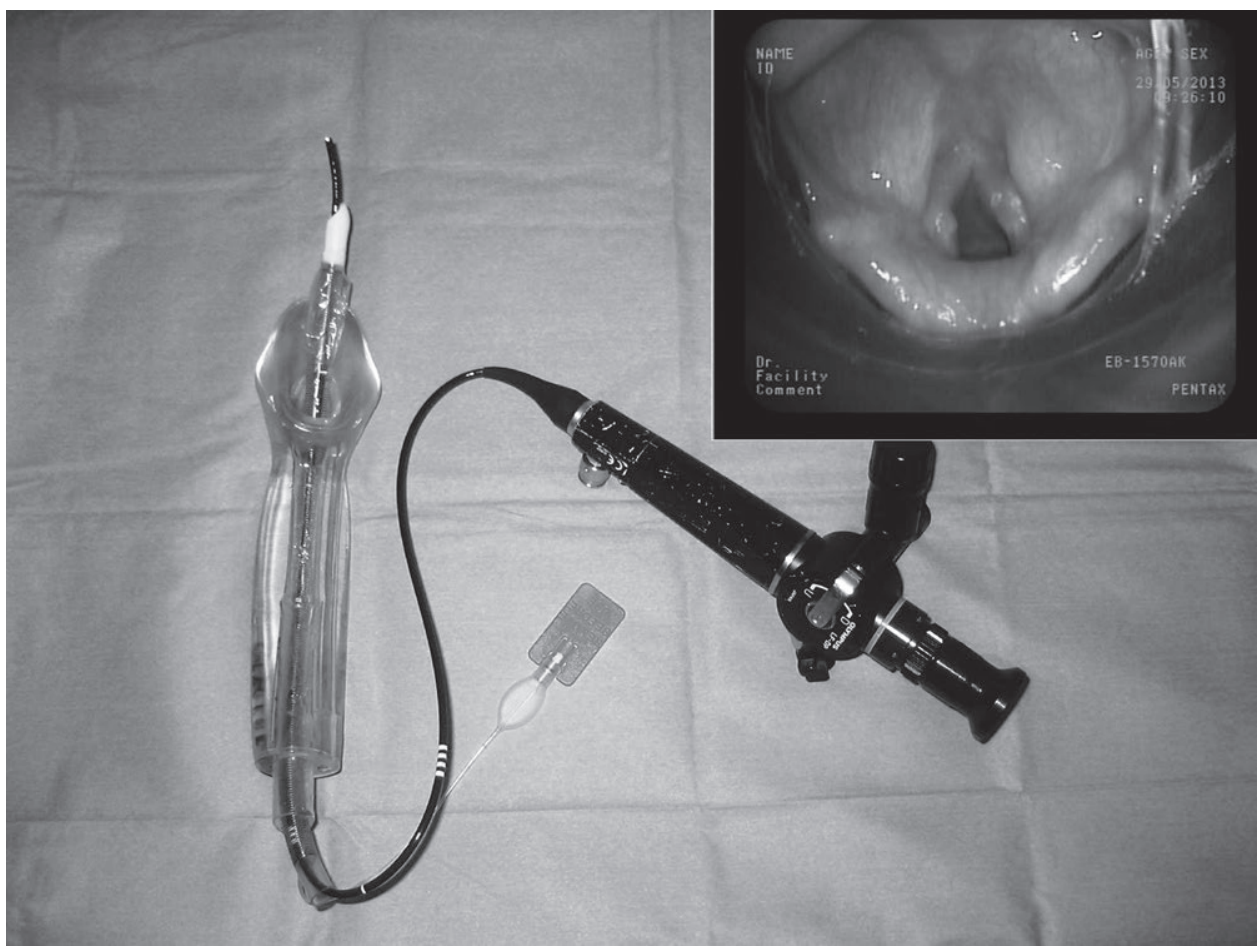

Figure 5 - Fibreoptic intubation through the i-gel and a view to the laryngeal inlet through the device.

Michálek P.; Donaldson W.; McAleavey F.; Abraham A.; Mathers R. J.; Telford C. 
(Cormack-Lehane scores 3 and 4) was carried out. In total 24 patients presented with difficult laryngoscopic views, 7 in the i-gel group, 12 in the sILMA group and 5 in the CTrach group, respectively. The i-gel was also inserted significantly faster than the other two devices in this sub-group and intubation times were also shorter (Table 5).

Post-hoc power analysis for primary and secondary outcomes was performed using final results of the study due to a significantly higher success rate in the i-gel group than expected. Based on the results of this study, a $95 \%$ success rate was considered as standard and $5 \%$ difference as significant. To detect this $5 \%$ difference at $95 \%$ significance and $80 \%$ power, 277 observations in each group and in total 834 patients would need to be recruited. Post-hoc analysis for secondary

Table 5 - Insertion time, intubation time, coverage of laryngeal inlet in the patients with difficult laryngoscopy (Cormack-Lehane grades 3, 4)

\begin{tabular}{lccc}
\hline & \multicolumn{3}{c}{ Device } \\
\cline { 2 - 4 } & i-gel $(\mathrm{n}=7)$ & sILMA $(\mathrm{n}=12)$ & CTrach $(\mathrm{n}=5)$ \\
\hline Time insertion $(\mathrm{s})$ & $12.3[11.6-13]$ & $24.8[20.9-28.7]$ & $24.8[23.8-25.8]$ \\
Difference & & $12.5[7.2-24.1]^{*}$ & $12.5[8.8-15]^{* * *}$ \\
Time intubation $(\mathrm{s})$ & $35.3[24.6-46]$ & $75.6[48.4-102.8]$ & $74.4[20.3-128.5]$ \\
Difference & & $40.3[14.4-68.5]^{*}$ & $39.1[1-137.6]^{*}$ \\
\hline
\end{tabular}

Data presented as mean (s) $[95 \% \mathrm{Cl}]$ for times; ${ }^{*} \mathrm{p}<0.05$, ${ }^{* * *} \mathrm{p}<0.001-$ Kruskal-Wallis test

Table 6 - Incidence of postoperative complaints at 6 and 24 hours after anaesthesia

\begin{tabular}{lrrrc}
\hline Symptom & i-gel (\%) & sILMA (\%) & CTrach (\%) & $\begin{array}{c}\text { Fisher's exact } \\
\text { test (P-value) }\end{array}$ \\
\hline & & 6 hours & \\
\hline Sore throat & 67.50 & 65.00 & 65.00 & 1.000 \\
Hoarse & 27.50 & 25.00 & 47.50 & $\mathbf{0 . 0 7 6}$ \\
Difficulty swallowing & 12.50 & 25.00 & 25.00 & 0.325 \\
Numb tongue & 0.00 & 2.50 & 5.00 & 0.772 \\
Cough & 10.00 & 32.50 & 17.50 & $\mathbf{0 . 0 5 4}$ \\
Nausea & 30.00 & 17.50 & 20.00 & 0.474 \\
\hline & \multicolumn{5}{c}{} & \\
\hline Sore throat & 32.50 & 22.50 & 37.50 & 0.385 \\
Hoarse & 2.50 & 5.00 & 15.00 & 0.144 \\
Difficulty swallowing & 2.50 & 2.50 & 5.00 & 1.000 \\
Numb tongue & 0.00 & 2.50 & 0.00 & 1.000 \\
Cough & 2.50 & 17.50 & 10.00 & $\mathbf{0 . 0 9 2}$ \\
Nausea & 2.50 & 10.00 & 10.00 & 0.389 \\
\hline
\end{tabular}


outcomes showed that given mean insertion time for the i-gel of $10 \mathrm{~s}$ (SD $4 \mathrm{~s}$, powered for $3 \mathrm{~s}$ difference between the groups) a minimum of 28 observations would be needed in each group. Similarly, for intubation time (SD $30 \mathrm{~s}$, difference $20 \mathrm{~s}$ ) at least 36 patients would be required in each group of patients.

Analysis of the incidence of postoperative complaints is reported in Table 6. There was no difference found at the level of significance of $5 \%$ between the groups at $24 \mathrm{~h}$. Some differences were observed at the $10 \%$ level of significance $(p<0.1)$. The incidence of hoarseness was higher in the CTrach group while patients with sILMA reported more cough than in the other two groups.

Serious perioperative complications such as significant intraoral bleeding, vomiting or aspiration were not seen in this cohort. One female patient in the CTrach group experienced decreased oxygen saturation $\left(\mathrm{spO}_{2} 91 \%\right)$ after intubation associated with harsh wheezes over the right hemithorax. During intubation, no gastric fluid was seen in the oral cavity. Postoperative X-ray showed consolidation within the right lower lobe. This patient required additional oxygen on the ward for the following two days.

\section{Discussion}

The results of this study suggest that all three devices are reasonably good conduits for fibrescope-guided tracheal intubation in patients with at least one predictor of difficult laryngoscopy. The i-gel was associated with shorter time of insertion, better coverage of glottic opening and reduced intubation time than both the sILMA and CTrach.

The ILMA (Intavent Orthofix Ltd., Wokingham, UK) has been designed for either blind or fibrescope-guided tracheal intubation, in patients with expected and unexpected difficult airway (Ferson et al., 2001). Since its development in 1997, it has been used for both blind and fibrescope-guided tracheal intubations in patients with a difficult airway. The ILMA is still considered as a "gold standard" among supraglottic airways used for tracheal intubation. The original ILMA was a reusable device, a single-use ILMA has been available since 2007 (Teoh and Lim, 2007).

The i-gel (Intersurgical Ltd., Wokingham, UK) is a supraglottic airway device, with an integrated channel for derivation of gastric fluid, with a wide breathing channel allowing direct passage of a tracheal tube (Donaldson et al., 2011; Michalek et al., 2013).

The CTrach (The Laryngeal Mask Company, Singapore) is a special device for difficult airway management (Liu et al., 2006). It has special optical fibres built-in inside its bowl and a liquid crystal display which allows views of the larynx while the endotracheal tube is being placed (Liu et al., 2009).

Standard laryngeal mask airway (cLMA, LMA Classic) may be also used as a rescue device in the cases of difficult intubation, however its design with a narrow lumen makes subsequent placement of endotracheal tube technically difficult.

With a reference to these supraglottic airway devices, only a few randomized 
studies and a small number of case reports detail tracheal intubation through the i-gel in patients with normal and potentially difficult airways. Initial manikin studies (de Lloyd et al., 2010; Michalek et al., 2010) compared i-gel with classical (cLMA) or intubating LMAs. De Lloyd et al. (2010) found fibrescope-guided intubation through the i-gel to be more successful and easier than through the cLMA. The i-gel was as successful as the ILMA for fibrescope-guided intubation while blind techniques with gum-elastic bougie or direct insertion of endotracheal tube through the device were significantly higher in the ILMA group (Michalek et al., 2010). Various authors have described fibrescope-guided tracheal intubation through the i-gel in patients with unpredicted difficult laryngoscopy (Sharma et al., 2007), craniofacial abnormities (Michalek et al., 2008), in the intensive care setting (Campbell et al., 2009) or in a "cannot intubate, cannot oxygenate" scenario (Corso et al., 2010). A few studies have focused on tracheal intubation through the i-gel in the operating room and its comparison with the ILMA. Both devices allowed high success rate of tracheal intubation using a fibrescope with similar intubation times (Kleine-Brueggeney et al., 2011). Limitations of this study may be that it used different tracheal tubes in each group and that predicted difficult laryngoscopy was not confirmed in the operating room. Another study showed significantly shorter intubation times and better visualisation of the glottis with the i-gel while total success rate was similar in both groups (Moore et al., 2015). This study did not specifically seek to recruit patients with predicted difficult intubation and used soft endotracheal tubes in both groups. Blind technique of endotracheal tube insertion was evaluated in two clinical trials. The ILMA was found to be superior to the i-gel as a conduit for blind insertion in the study by Theiler et al. (2011).

In the second study, the authors reported similar success rate of tracheal intubation through the devices on the first attempt, while total success rate was significantly higher with the ILMA (Halwagi et al., 2012).

Our study has several limitations. The sample size was not big enough to prove a difference in the success rate but sufficient for confirmation of difference in insertion and intubation times. Another limitation may be that the operators were more experienced in insertion of the i-gel for routine procedures under general anaesthesia in comparison with the other two devices. However, all operators had similar experience with fibreoptic intubation through each device studied. Operators performing the intubations were all relatively experienced in airway management and the results might be different with inexperienced trainees or novices in anaesthesia.

On the other hand, our study used identical soft endotracheal tubes in all patients and thus created comparable intubation conditions between the groups. Predicted difficulties were verified using direct laryngoscopy in order to validate the use of these SADs in real difficult intubation scenarios which was not performed in other published studies. 


\section{Conclusion}

The i-gel, sILMA and LMA CTrach allow fibrescope-guided tracheal intubation with a very high first attempt, total success rate and overall low incidence of complications (Michalek et al., 2015). The i-gel device showed best coverage of the laryngeal inlet, as well as shortest insertion and intubation time. Based on the results of our study and other trials this device may become a first option SAD in difficult or failed laryngoscopy.

\section{References}

Campbell, J., Michalek, P., Deighan, M. (2009) I-gel supraglottic airway for rescue airway management and as a conduit for tracheal intubation in a patient with acute respiratory failure. Resuscitation 80, 963.

Cormack, R. S., Lehane, J. (1984) Difficult tracheal intubation in obstetrics. Anaesthesia 39, 1105-1111.

Corso, R. M., Piraccini, E., Agnoletti, V., Gambale, G. (2010) Use of an i-gel in a "can't intubate/can't ventilate” situation. Anaesth. Intensive Care 38, 212.

de Lloyd, L., Hodzovic, I., Voisey, S., Wilkes, A. R., Latto, I. P. (2010) Comparison of fibrescope guided intubation via the classic laryngeal mask airway and i-gel in a manikin. Anaesthesia 65, 36-43.

Donaldson, W., Abraham, A., Deighan, M., Michalek, P. (2011) i-gel ${ }^{T M}$ versus AuraOnce $^{\text {TM }}$ laryngeal mask for general anaesthesia with controlled ventilation in paralyzed patients. Biomed. Pap. Med. Fac. Univ. Palacky Olomouc Czech Repub. 155, 155-163.

Ferson, D. Z., Rosenblatt, W. H., Johansen, M. J., Osborn, I., Ovassapian, A. (2001) Use of the intubating LMA-Fastrach in 254 patients with difficult-to-manage airways. Anesthesiology 95, 1175-1181.

Frerk, C., Mitchell, V. S., McNarry, A. F., Mendonca, C., Bhagrath, R., Patel, A., O’Sullivan, E. P., Woodall, N. M., Ahmad, I. (2015) Difficult Airway Society 2015 guidelines for management of unanticipated difficult intubation in adults. Br. J. Anaesth. 115, 827-848.

Halwagi, A. E., Massicotte, N., Lallo, A., Gauthier, A., Boudreault, D., Ruel, M., Girard, F. (2012) Tracheal intubation through the i-gel ${ }^{\mathrm{TM}}$ supraglottic airway versus the LMA Fastrach ${ }^{\mathrm{TM}}$ : a randomized controlled trial. Anesth. Analg. 114, 152-156.

Kapila, A., Addy, E.V., Verghese, C., Brain, A. I. J. (1997) The intubating laryngeal mask airway: an initial assessment of performance. Br. J. Anaesth. 79, 710-713.

Kleine-Brueggeney, M., Theiler, L., Urwyler, N.,Vogt, A., Greif, R. (2011) Randomized trial comparing the i-gel $^{T M}$ and Magill tracheal tube with the single-use ILMA ${ }^{T M}$ and ILMA ${ }^{T M}$ tracheal tube for fibreopticguided intubation in anaesthetized patients with a predicted difficult airway. Br. J. Anaesth. 107, $251-257$.

Levitan, R. M., Ochroch, E. A., Kush, S., Shoffer, F. S., Hollander, J. E. (1998) Assessment of airway visualization: validation of the percentage of glottic opening (POGO) scale. Acad. Emerg. Med. 5, 919-923.

Liu, E. H., Goy, R.W., Chen, F. G. (2006) The LMA CTrach, a new laryngeal mask airway for endotracheal intubation under vision: evaluation in 100 patients. Br. J. Anaesth. 96, 396-400.

Liu, E. H., Wender, R., Goldman, A. J. (2009) The LMA CTrach in patients with difficult airways. Anesthesiology 110, 941-943.

Michalek, P., Hodgkinson, P., Donaldson,W. (2008) Fiberoptic intubation through an i-gel supraglottic airway in two patients with predicted difficult airway and intellectual disability. Anesth. Analg. 106, 1501-1504.

Michalek, P., Donaldson, W., Graham, C., Hinds, J. D. (2010) A comparison of the i-gel supraglottic airway as a conduit for tracheal intubation with the intubating laryngeal mask airway: a manikin study. Resuscitation 81, 74-77.

Michalek, P., Donaldson, W., Theiler, L. G. (2013) The use of i-gel in anaesthesia - facts and fiction in 2013. Trends Anaesth. Crit. Care 3, 246-251. 
Michálek, P., Miller, D. M. (2014) Airway management evolution - In a search for an ideal extraglottic airway device. Prague Med. Rep. 115, 87-103.

Michalek, P., Donaldson, W., Vobrubova, E., Hakl, M. (2015) Complications associated with the use of supraglottic airway devices in perioperative medicine. Biomed Res. Int. 2015, 746560.

Moore, A., Gregoire-Bertrand, F., Massicotte, N., Gauthier, A., Lallo, A., Ruel, M., Todorov, A., Girard, F. (2015) i-gel versus LMA Fastrach supraglottic airway for flexible bronchoscope-guided tracheal intubation using a Parker (GlideRite) endotracheal tube: a randomized controlled trial. Anesth. Analg. 121, 430-436.

Sharma, S., Scott, S., Rogers, R., Popat, M. (2007) The i-gel airway for ventilation and rescue intubation. Anaesthesia 62, 419-420.

Teoh,W. H., Lim, Y. (2007) Comparison of the single use and reusable intubating laryngeal mask airway. Anaesthesia 62, 381-384.

Theiler, L., Kleine-Brueggeney, M., Urwyler, N., Graf, T., Luyet, C., Greif, R. (2011) Randomized clinical trial of the i-gel ${ }^{T M}$ and Magill tracheal tube or single-use ILMA ${ }^{T M}$ and ILMA ${ }^{T M}$ tracheal tube for blind intubation in anaesthetized patients with a predicted difficult airway. Br. J. Anaesth. 107, 243-250.

Timmermann, A. (2011) Supraglottic airways in difficult airway management: successes, failures, use and misuse. Anaesthesia 66, 45-56 (Suppl. 2). 